\title{
Políticas públicas e ações de incentivo à leitura promovidas por organizações empresariais sob a ótica da responsabilidade social
}

\author{
Public Policies and reading incentive actions of business organizations as part of their social \\ responsibility strategy
}

Adam Felipe Ferreira
Mestrando do Programa de Pós-Graduação em Ciência da Informação pela Faculdade de Filosofia e Ciências da
Universidade Estadual Paulista "Júlio de Mesquita Filho" - UNESP, campus de Marília.
E-mail: adam.f.ferreira@ @hotmail.com

Íris Marques Tavares Sardelari

Mestranda do Programa de Pós-Graduação em Ciência da Informação pela Faculdade de Filosofia e Ciências da Universidade Estadual Paulista "Júlio de Mesquita Filho" - UNESP, campus de Marília.

E-mail: irismtavares@hotmail.com

Claudio Marcondes de Castro Filho

Doutor em Ciência da Informação pela Universidade de São Paulo - USP

Professor do curso de Biblioteconomia e Ciências da Informação e da Documentação da FFCLRP/USP e do Programa de Pós-Graduação em Ciência da Informação pela Faculdade de Filosofia e Ciências da Universidade Estadual Paulista "Júlio de Mesquita Filho" - UNESP, campus de Marília. E-mail: claudiomarcondes@ ffclrp.usp.br

\section{Resumo}

Contextualização: A descoberta da imprensa possibilitou o acesso a obras literárias e à informação, antes restritas aos detentores do poder, como ordens religiosas, reis ou nobres. Entretanto, os altos índices de analfabetismo ainda eram uma barreira para que cada vez mais pessoas tivessem acesso à informação. Até meados do século XX, metade da população brasileira ainda era analfabeta, mas o estabelecimento de políticas públicas e ações da iniciativa privada contribuíram para mudar esta realidade. Objetivo: O objetivo deste artigo é discorrer sobre políticas públicas e ações de incentivo à leitura promovidas por organizações empresariais, no âmbito de suas estratégias de responsabilidade social, que contribuíram para a mudança dessa realidade. Metodologia: por meio de uma pesquisa de natureza exploratória e qualitativa, elaboramos uma revisão da literatura com o objetivo de apresentar as políticas públicas voltadas ao incentivo à leitura, bem como, com base no ranking da Revista Fortune das maiores empresas, escolhemos as 7 empresas brasileiras constantes desse ranking para demonstrar o que elas têm feito para incentivar a leitura no Brasil. Resultados: No âmbito das políticas públicas de incentivo à leitura, no período de 2006 a 2010, verificou-se que a cadeia do livro passou a ser valorizada enquanto negócio rentável; houve a instalação de grandes grupos editorias e apoio de organismos internacionais como OEI, UNESCO, entre outros. A partir de 2012, os incentivos públicos se concentraram em ações mais descentralizadas, como realização de reuniões, seminários e encontros. No âmbito das ações de incentivo à leitura da iniciativa privada as 7 organizações estudadas apresentaram ações específicas voltadas ao incentivo à leitura. Conclusão: As ações da iniciativa privada juntamente com as políticas públicas desenvolvidas e implementadas no Brasil ainda acontecem de forma muito tímida, comparadas com a realidade desta sociedade, que possui em sua grande maioria indivíduos com dificuldades e limitações para a escrita, leitura e reflexão.

Palavras-chave: Políticas Públicas. Responsabilidade Social. Leitura. 


\begin{abstract}
Contextualization: The discovery of the press provides access to literary works and information, previously restricted to those in power, as religious orders, kings or nobles. However, the high illiteracy rates were still a barrier to more people had access to information. Until the mid-twentieth century, half the population was still illiterate, but the establishment of public policies and private sector initiatives have contributed to change this reality. Objective: this article aims to discuss public policy and reading incentive actions taken by business organizations, as part of their social responsibility strategy, which contributed to change that reality. Methodology: Through an exploratory and qualitative research, we developed a literature review with the aim of presenting the public policies aimed at encouraging reading, and based on the Fortune Magazine of the largest companies, we chose seven Brazilian companies that were in this ranking to demonstrate what they have done to encourage reading in Brazil. Results: Regarding public policies to encourage reading in the period 2006-2010, book industry became valued as a profitable business; there was the installation of large editorial groups and support from international organizations such as OEI, UNESCO, among others. From 2012, public incentives focused on more decentralized actions, such as meetings, seminars and meetings. Regarding measures to encourage reading of the private sector, all organizations studied presented specific actions aimed at encouraging reading. Conclusion: The actions of the private sector and the public policies developed and implemented in Brazil still happen very timid compared to the reality of this society, which has mostly individuals with difficulties and limitations for writing, reading and reflection.
\end{abstract}

Keywords: Public Policy. Social Responsibility. Reading.

\title{
Introdução
}

Ao longo dos anos, a Sociedade tem sido denominada principalmente de acordo com os seus insumos econômicos. Quando sua base econômica era a Agricultura, foi denominada de Sociedade Agrícola. Durante a revolução industrial, passou a ser denominada de Sociedade Industrial. Na Terceira Onda, como sua base econômica é a informação, recebeu o nome de Sociedade da Informação ou ainda Sociedade do Conhecimento, dentre outros termos.

$\mathrm{Na}$ atualidade, a informação configurou-se como elemento fundamental, assumindo ao longo dos anos um importante papel na vida das pessoas, estando presente de maneira intensiva em todos os aspectos e em todos os momentos de forma exaustiva. Nessa sociedade, a informação se configura como um insumo capaz de proporcionar uma transformação social. Mas, para isso, o desenvolvimento da competência em informação nas pessoas é essencial, pois não significa somente garantir o acesso à informação, mas ensiná-las a utilizá-la e aplicá-la ao seu contexto social.

A capacidade de leitura, vinculada ao universo da informação, se configura, então, como uma competência essencial para que se consiga utilizar a informação em toda a sua potencialidade, pois quando os indivíduos não possuem a capacidade de ler e, assim, não têm acesso à informação, torna-se difícil formar cidadãos de fato e de direito. 
Políticas públicas e ações de incentivo à leitura promovidas por organizações empresariais sob a ótica da responsabilidade social

Diante disso, esse artigo tem como objetivo discorrer sobre políticas públicas e ações de incentivo à leitura promovidas por organizações empresariais, no âmbito de suas estratégias de responsabilidade social.

Para isso, por meio de uma pesquisa de natureza exploratória e qualitativa, elaboramos uma revisão da literatura com o objetivo de apresentar as políticas públicas voltadas ao incentivo à leitura, bem como, com base no ranking de 2015 das 500 maiores empresas segundo a Revista Fortune, escolhemos as 7 empresas brasileiras constantes desse ranking para demonstrar o que elas têm feito para incentivar a leitura no Brasil.

Além disso, o tema desse artigo se justifica, pois, apesar da obtenção de avanços, como a diminuição do índice de analfabetismo, que passou de 50\% em 1950 para 6\% em 2011, o índice de livros lidos por ano no Brasil ainda é baixo, de apenas 3,1, conforme pesquisa Retratos da Leitura no Brasil, edição de 2011.

\section{Informação e Leitura}

Terceira Onda, Era da Informação ou Sociedade da Informação, Sociedade em Rede, Sociedade do Conhecimento, Sociedade da Aprendizagem e Economia Informacional são alguns termos usados para descrever uma nova Era, marcada por grandes mudanças (COUTINHO; LISBÔA, 2011).

Nessa Sociedade, seu insumo econômicoprincipal é a informação, que, além de levar à criação de riquezas e prosperidade, proporciona a inclusão social, isto é, a cidadania.

Corroborando-se a isso, para Bourdieu (1998 apud HOLANDA; OLIVEIRA, M.; OLIVEIRA, S., 2013, p.49), o acesso à informação é capaz de dividir uma sociedade entre aqueles que possuem mais ou menos informações.

Belluzzo (2014, p. 51) afirma que somente os acessos à informação ou ao conhecimento não são suficientes, mas deve-se saber qual o uso e significado da informação para saber entendê-la e disseminá-la.

Assim, a utilização da informação pressupõe o desenvolvimento nos indivíduos da Competência em Informação (CoInfo), que se constituiem um: 
Adam Felipe Ferreira, Íris Marques Tavares Sardelari e Claudio Marcondes de Castro Filho

[...] processo contínuo de interação e internalização de fundamentos conceituais, atitudinais e de habilidades específicas como referenciais à compreensão da informação e de sua abrangência, em busca da fluência e das capacidades necessárias à geração do conhecimento novo e sua aplicabilidade ao cotidiano das pessoas e das comunidades ao longo da vida (BELLUZO, 2005, p.38).

A capacidade de leitura, vinculada ao universo da informação, se configura, então, como uma competência essencial para que se consiga utilizar a informação em toda a sua potencialidade, ou seja, Castro Filho e Romão (2011, p. 137) sustentam que "os gestos de leitura sempre se apoiam em saberes e dizeres já falados antes, sendo que ao leitor cabe renegociar o já-sabido com o texto/livro/enunciado que tem em mãos”.

De acordo com Castro Filho (2008, p. 83), “as leituras são essenciais no início do desenvolvimento intelectual do sujeito, e o entreter da leitura direciona do mágico para o real, que tem como base principal, informar, independente dos suportes que se pode oferecer". Para Manguel (1997), na análise que elabora da maneira de ler de Santo Agostinho, relata que "tomando do livro uma ideia, uma frase, uma imaginação, ligando-se a outro texto preservado na memória, amarrando o conjunto com reflexões próprias, produzirá na verdade, um texto novo de autoria do leitor".

"Leitores inferem, deduzem, completam vão e voltam, "levantam a cabeça" (como bem disse Roland Barthes), rabiscam, subvocalizam, aumentam ou diminuem o ritmo" (RIBEIRO, 2011, p.100).

Nesse aspecto, a leitura passa a contribuir para a formação do indivíduo como uma atitude positiva, de reconhecimento de novas possibilidades, de interpretação do material conhecido e de descobrimento de novos caminhos para entender e interpretar a leitura.

A descoberta da imprensa possibilitou que mais pessoas tivessem acesso aos textos, que, devido aos pouquíssimos exemplares das obras, tinham acesso restrito, pertencendo aos detentores do poder à época, como ordens religiosas, reis ou nobres. Apesar de junto com a revolução mercantil, que marcou o início da modernidade, ter começado a ascensão da burguesia e do regime político democrático, permitindo o acesso de mais pessoas a essas obras, ainda assim poucaspessoas tinham acesso aos livros, devido aos altos índices de analfabetismo. 
Políticas públicas e ações de incentivo à leitura promovidas por organizações empresariais sob a ótica da responsabilidade social

\section{Retratos da Leitura no Brasil}

Criado em 2006 pelas entidades do livro Abrelivros, CBL e SNEL, o Instituto Pró-Livro (IPL) tem como objetivo o fomento à leitura e à difusão do livro no Brasil. Em 2011, o IPL foi o responsável pela elaboração da terceira edição da Pesquisa Retratos da Leitura no Brasil, que evidencia o comportamento do leitor no país desde 2000, ano de realização da primeira edição da pesquisa.

Além de demonstrar o comportamento do leitor, a pesquisa também mede a intensidade, forma, motivação e condições de leitura da população brasileira, bem como traça o perfil dos leitores de livros digitais, além de avaliar a percepção dos usuários de bibliotecas públicas (INSTITUTO PRÓ-LIVRO, 2012, p. 20).

Em relação aos conceitos, em 2011, a pesquisa definiu como leitor aquele que declarou, no ato da pesquisa, ter lido pelo menos um livro nos últimos três meses. E, não-leitor aquele que declarou não ter lido nenhum livro nos últimos três meses. Dessa forma, o índice de leitura tem como referência a leitura dos últimos três meses anteriores à pesquisa (INSTITUTO PRÓLIVRO, 2012, p. 21).

A partir da segunda edição (2007), realizada pelo recém-criado Instituto Pró-Livro, a pesquisa adotou uma metodologia desenvolvida pela UNESCO e pela Organização dos Estados Ibero-americanos (OEI), com o objetivo de orientar as pesquisas sobre leitura realizadas na América Latina. Com isso, a pesquisa buscou alcançar um padrão internacional de medição a fim de comparar a questão da leitura nos países da região.

Considerando-se as diferenças metodológicas entre as edições, visando apresentar uma comparação entre elas, o IPL, em 2011, separou na $3^{\circ}$ edição da pesquisapara estudo em cada amostra um grupo com o mesmo perfil: população acima de 15 anos, com no mínimo 3 anos de escolaridade, que leu pelo menos 1 livro nos últimos 3 meses. Os resultados desta comparação constam da tabela 4.

Tabela 1 - Comparação 2000-2007-2011 da quantidade de livros/ano lidos no período de 3 meses

\begin{tabular}{ccc}
\hline Edição da Pesquisa & Quantidade de leitores & Quantidade de livros/ano \\
\hline 2011 & 71,9 milhões & 3,1 \\
2007 & 66,5 milhões & 3,7 \\
2000 & 26 milhões & 1,8
\end{tabular}

Fonte: Instituto Pró-Livro (2012, p. 73) 
Adam Felipe Ferreira, Íris Marques Tavares Sardelari e Claudio Marcondes de Castro Filho

Os dados acima mostram que o índice de leitura piorou da segunda (2007) para a terceira edição (2011) da pesquisa, passando de 3,7 para 3,1 quantidade de livros lidos por ano. Além disso, ao analisar o índice considerando-se as diferenças de raça/cor, renda, gênero, escolaridade, regiões, a pesquisa concluiu que quanto mais rico é o entrevistado, maior é a penetração da leitura e média de livros lidos nos últimos três meses(INSTITUTO PRÓ-LIVRO, 2012, p. 144).

A pesquisa Retratos da Leitura no Brasil, bem como aquelas realizadas pelo IBGE sobre escolaridade, alfabetismo e indicadores sociais e econômicos, têm subsidiado a criação de políticas públicas de leitura no nosso país.

\section{Políticas Públicas de Leitura no Brasil}

Segundo Holanda, Oliveira e Oliveira (2013, p. 48), o povo procura no Estado apoio para suprir as suas necessidades, visando alcançar o seu direito à cidadania. Dessa forma, a política social faz parte das políticas públicas, que, segundo Saravia (2006, p. 28-29), consistem em:

[...] um fluxo de decisões públicas, orientado a manter o equilíbrio social ou a introduzir desequilíbrios destinados a modificar essa realidade. Decisões condicionadas pelo próprio fluxo e pelas reações e modificações que elas provocam no tecido social, bem como pelos valores, ideias e visões dos que adotam ou influem na decisão. É possível considerá-las como estratégias que apontam para diversos fins, todos eles, de alguma forma, desejados pelos diversos grupos que participam do processo decisório. Com uma perspectiva mais operacional, poderíamos dizer que ela é um sistema de decisões públicas que visa a ações ou omissões, preventivas ou corretivas, destinadas a manter ou modificar a realidade de um ou vários setores da vida social, por meio da definição de objetivos e estratégias de atuação e da alocação dos recursos necessários para atingir os objetivos estabelecidos.

Este fluxo de decisões públicas quando voltado às ações sociais recebe o nome de políticas públicas sociais. Para Holanda, Oliveira e Oliveira (2013, p. 48),as políticas públicas sociais não se restringem somente ao Estado, pois atuam "de e para" todos nas políticas voltadas à universalização dos direitos sociais.

Secchi (2014, p. 2) define política pública como uma "diretriz elaborada para enfrentar um problema público que possui dois elementos fundamentais: intencionalidade pública e resposta a um problema público".

Holanda, Oliveira e Oliveira (2013, p. 49) defendem que as políticas sociais relacionadas ao direito à informação são voltadas à viabilização do acesso aos instrumentos 
Políticas públicas e ações de incentivo à leitura promovidas por organizações empresariais sob a ótica da responsabilidade social

sociais e suportes comunicacionais que, por meio da informação, proporcionam uma transformação social.

Nesse sentido, informação, leitura e cidadania se complementam, pois quando os indivíduos não possuem a capacidade de ler e, assim, não têm acesso à informação, torna-se difícil formar cidadãos de fato e de direito. Wethein (2008, p. 48) defende que, por meio dos livros, se chega ao conhecimento e este é caminho para que "os conflitos naturais da vida em sociedade resultem em crescimento do bem-estar e redução das desigualdades".

O Brasil, ao longo dos anos, criou e implantou diversas políticas públicas para o livro, leitura, literatura e biblioteca. Oliveira e Prados (2015, p. 104) elencam as seguintes:

- Criação do Instituto Nacional do Livro (INL) em 1937;

- Implantação de pequenas bibliotecas a partir as primeiras décadas do século XX;

- Descentralização das atividades do INL a partir do final da década de 60 e início da década de 70, para o campo das bibliotecas. Foram criados: o Sistema Nacional de Bibliotecas Públicas - SNBP (1976), Sistemas Estaduais de Bibliotecas Pública - SEBP;

- Fundação Pró-Leitura (1988);

- Fundação Biblioteca Nacional (1990). Neste período foram extintos o INL, SNBP e Fundação Pró-Leitura, sendo as atividades desses institutos centralizadas pela Fundação Biblioteca Nacional.

- Política Nacional do Livro (Lei no 10.753, a Lei do Livro) em 2003.

- Plano Nacional do Livro e Leitura (PNLL) em 2006. Em 2012, a Diretoria do Livro, Leitura e Literatura (DLLL) incorporou o SNBP, acrescentando então o "B" ao Plano, passando a ser chamado de Plano Nacional do Livro, Leitura, Literatura e Biblioteca (PNLLLB).

Em 2014, os Ministérios da Cultura e da Educação publicaram uma edição atualizada e revisada do Plano Nacional do Livro e Leitura (PNLL).

O PNLL reúne diretrizes para uma política pública voltada à leitura e à literatura no Brasil e, em particular, à biblioteca e à formação de mediadores. Essas diretrizes consideram a importânciadessas instâncias para o desenvolvimento social e da cidadania, pois a formação de uma sociedade leitora é condição essencial para a "inclusão social de milhões de brasileiros no que diz respeito a bens, serviços e cultura, garantindo-lhes uma vida digna e a estruturação de um país economicamente viável” (PNLL, 2014, p. 2).

Diante desse contexto, o PNLL (2014, p. 27) estabeleceu quatro eixos: a) democratização do acesso; b) fomento à leitura e á formação de mediadores; c) valorização institucional da leitura e o incremento de seu valor simbólico; d) desenvolvimento da economia do livro como estímulo à produção intelectual e ao desenvolvimento nacional; que orientam a sua organização, e dentro de cada eixo as ações. 
Adam Felipe Ferreira, Íris Marques Tavares Sardelari e Claudio Marcondes de Castro Filho

Além desses eixos e ações, o PNLL (2014, p. 15) valoriza cinco fatores identificados pela UNESCO:

a) o livro deve ocupar destaque no imaginário nacional, sendo valorizado por
amplas faixas da população;
b) devem existir famílias leitoras que compartilhem práticas de leitura, de modo que
as gerações se influenciem mutuamente e construam representações afetivas em
torno da leitura;
c) deve haver escolas que saibam formar leitores, valendo-se de mediadores bem
formados (professores, bibliotecários, mediadores de leitura) e de múltiplas
estratégias e recursos para alcançar essa finalidade.
d) deve ser garantido o acesso ao livro, com um número suficiente de bibliotecas e
livrarias;
e) o preço do livro deve ser acessível a grandes contingentes de potenciais leitores.

Além desses eixos, ações e fatores, as políticas voltadas para o livro, leitura, literatura e bibliotecas seguem as diretrizes da competência em informação e do aprendizado ao longo da vida, que têm recebido especial atenção da UNESCO em diretrizes e políticas mundiais voltadas para o desenvolvimento, prosperidade e liberdade e para criar condições plenas de inclusão social (PNLL, 2014, p. 15).

Conscientes de que as políticas públicas não têm sido suficientes para o alcance do objetivo de assegurar e democratizar o acesso à leitura, ao livro, à literatura e às bibliotecas a toda a sociedade, organizações do terceiro setor e da iniciativa privada, no âmbito da responsabilidade social, têm realizado ações que contribuam para o alcance desse objetivo.

\section{Responsabilidade Social}

A Responsabilidade Social (RS) refere-se ao cumprimento dos deveres e obrigações dos indivíduos enquanto seres sociais e das organizações para com a coletividade. Diz respeito ao exercício cidadão e ao pensar sustentável pautado na ética e na legalidade.

Concretiza-se por meiode ações, tomadas de decisões, comportamentos e práticas construtivas, que contribuem de forma eficaz para a preservação e melhoria do bem-estar de todos.

Para Ashley (2002, p.6):

responsabilidade social pode ser definida como o compromisso que uma organização deve ter para com a sociedade, expresso por meio de atos e atitudes que a afetam positivamente, de modo amplo, ou a alguma comunidade, de modo específico, agindo pró-ativamente e coerentemente no que tange ao seu papel específico na sociedade e a sua prestação de contas para com ela. 
Políticas públicas e ações de incentivo à leitura promovidas por organizações empresariais sob a ótica da responsabilidade social

Ela acontece de forma voluntária pelas organizações, uma vez que adotam posturas integralizadoras que beneficiam seu público interno ou externo no que tange àsociedade. Por ser composta de ações voluntárias, não deve ser confundida comomedidas compulsórias impostas pelo governo, pois a responsabilidade social transcende essas questões, já que sua essência está na transformação daspessoas em agentes socialmente ativos que buscam um ambiente mais digno e sustentável para todos.

No cenário mundial contemporâneo, observam-se inúmeras transformações nas esferas econômicas, políticas, sociais, culturais que modificam as relações e as formas de trabalho. De acordo com Melo Neto (2001, p. 26), a responsabilidade social deve ser entendida pelas organizações como:

a forma ética e responsável pela qual a empresa desenvolve todas as suas ações, políticas, suas práticas, suas atitudes, tanto com a comunidade quanto com o seu corpo funciona. Enfim, com o ambiente interno e externo à organização, e com todos os agentes interessados no processo.

O ambiente organizacional atual anseia por um pensar pautado na postura cidadã, sustentável com responsabilidades voltadas à coletividade. Houve um despertar para o coletivo, as organizações agora precisam alcançar convergência entre metas econômicas e sociais.

Segundo o Instituto Ethos (2016, p. 8), um negócio sustentável e responsável consiste emuma:

[...] atividade econômica orientada para a geração de valor econômicofinanceiro, ético, social e ambiental, cujos resultados são compartilhados com os públicos afetados. Sua produção e comercialização são organizadas de modo a reduzir continuamente o consumo de bens naturais e de serviços ecossistêmicos, a conferir competitividade e continuidade à própria atividade e a promover e manter o desenvolvimento sustentável da sociedade.

Com o passar do tempo, o termo responsabilidade social modificou-se e amadureceu em sua essência e em seus principais objetivos, ocasionando algumas variações complementares ou distintas. Entre esses termos estão:

- Responsabilidade Social Empresarial (RSE): está diretamente relacionada com o público interno de sua empresa, sejam eles funcionários; colaboradores; dentre outros.

- Responsabilidade Social Corporativa (RSC): conceito frequentemente utilizado por grandes organizações (denominadas de grande porte), que se fundamenta em ações voltadas em benefício à economia local; ao meio ambiente; moradia; transporte; educação; políticas públicas em geral que contribuem positivamente para a melhoria da sociedade e organizações.

- Responsabilidade Social Ambiental (RSA): tem seus princípios e valores arraigados em preocupações com a preservação e manutenção do meio ambiente, ações intimamente ligadas com o pensar sustentável. 
A sociedade atual exige de seus indivíduos uma nova forma de pensar e agir, uma vez que a globalização é um marco na era contemporânea e a responsabilidade social, pautada na postura cidadã e no exercício sustentável, engloba práticas que abrem caminho para uma sociedade mais humana e igualitária, pois a globalização e seus benefícios devem ser fatores de inclusão e não de exclusão, sendo necessário estabelecer comportamentos baseados em princípios e valores coletivos, criar noções de integralização, pois a dignidade é um direito elementar à vida de qualquer cidadão.

De modo a contribuir para a consolidação da responsabilidade social, foram criadas diversas regulamentações que reconhecem uma organização como sendo socialmente responsável. Dentre os indicadores mais destacados desta área, ressaltam-se os Indicadores Ethos de Responsabilidade Social, reconhecido como o mais importante, que classifica anualmente as ações e organizações envolvidas em questões sociais e seu grau de comprometimento.

Esses indicadores captam informações nas seguintes dimensões: a) Visão e estratégia; b) Governança e Gestão; c) Social; e d) Ambiental (INSTITUTO ETHOS, 2016, p. 14-15).

Dentre as tendências de mercado e com a intenção de estabelecer sempre uma padronização dos processos organizacionais por meio de selos e especificações técnicas, surgiram as certificações socioambientais que buscam, além da adequação das normas de excelência, a divulgação das boas práticas empresariais pautadas nos princípios da responsabilidade social.

Uma organização voltada para o desenvolvimento da responsabilidade social planeja emseus negócios um horizonte multidimensional e integrado, proporcionando, assim, uma visão holística sobre a ambiência empresarial, transformando suas ações em estratégias para o exercício da vantagem competitiva, assegurando os direitos civis; econômicos; sociais; políticos e ambientais, contribuindo efetivamente para uma sociedade mais justa e igualitária. 
Políticas públicas e ações de incentivo à leitura promovidas por organizações empresariais sob a ótica da responsabilidade social

\section{Procedimentos Metodológicos}

O método científico pode ser compreendido por um conjunto de elementos seguidos por uma habilidade crítica e inovadora empenhada na descoberta da veracidade e na construção do pensamento científico.

Segundo Andrade (2009, p. 109), "pesquisa é o conjunto de procedimentos sistemáticos, baseado no raciocínio lógico que tem por objetivo encontrar soluções para problemas propostos, mediante a utilização de métodos científicos [...]”.

Esta pesquisa, de natureza exploratória e qualitativa, teve como objetivoo aprimoramento das ideias, promovendo uma discussão sobre políticas públicas brasileiras e ações de incentivo à leitura promovida por organizações empresariais sob a ótica da responsabilidade social.

Para estudo e análise, realizamos uma revisão da literatura sobre as políticas públicas de incentivo à leitura no Brasil, trazendo, na seção de Discussão os resultados obtidos com a implementação do Plano Nacional do Livro, Leitura, Literatura e Biblioteca (PNLL) até 2015. Buscamos também compreender o cenário da leitura no Brasil por meio da $3^{\text {a }}$ Edição da Pesquisa Retratos da Leitura no Brasil, realizada pelo Instituto Pró-Livro em 2011.

No que tange às ações de incentivo à leitura promovidas pelas organizações empresariais, realizamos uma revisão da literatura sobre Responsabilidade Social para entender os objetivos e interesses dessas organizações em se envolver nessa temática.

Para apontar o envolvimento da iniciativa privada, a escolha das empresas se pautou no ranking da revista Fortune, revista americana sobre negócios, que elege anualmente as 500maiores empresas do mundo com base em indicadores financeiros. As organizações privadas analisadas neste trabalho foram escolhidas com base na existência de empresas brasileiras que constavam no ranking das 500 maiores da Fortune para o ano fiscal que se encerrou em março de 2015, sendo que entre elas constavam7 organizações empresariais brasileiras (respectivamente: Petrobrás (28 no ranking), Itaú $\left(112^{\mathrm{a}}\right)$, Banco do Brasil $\left(126^{\mathrm{a}}\right)$, Banco Bradesco $\left(185^{\mathrm{a}}\right)$, JBS $\left(202^{\mathrm{a}}\right)$, Vale $\left(312^{\mathrm{a}}\right)$ e Ultrapar $\left.\left(414^{\mathrm{a}}\right)\right)$, que foram elencadas e estudadas neste trabalho por meio de suas ações voltadas ao incentivo da leitura no país (SALOMÃO, 2015). 
Adam Felipe Ferreira, Íris Marques Tavares Sardelari e Claudio Marcondes de Castro Filho

Os resultados apresentados foram baseados em consultas nos sites de organizações públicas, quando buscávamos informações das políticas públicas, e nos sites das empresas escolhidas, quando buscávamos exemplos de ações de incentivo à leitura.

Ressaltamos que, devido às limitações deste trabalho, os dados foram obtidos exclusivamente dos sites das organizações, por isso, pode ser que as empresas ou organizações públicas citadas tenham desenvolvido outras ações, mas não as citamos por não as encontrarmos divulgadas nesses sites no período que definimos para a pesquisa (novembro de 2015).

\section{Discussões e Resultados}

Em 2010, José Castilho Marques Neto organizou e publicou o livro PNLL: textos e histórias, com o objetivo de apresentar o Plano, bem como os resultados obtidos no período de 2006 a 2010. Entre as conquistas Rösing (2010, p. 235-240) elencou:

- atmosfera favorável à leitura nos mais distintos recantos do Brasil e da América Latina;

- ampliação do número de feiras do livro sustentadas por seminários e conferências em espaços inusitados;

- consolidação das bienais do livro;

- materiais de leitura diversificados são disponibilizados em espaços públicos como escritórios, cafés, clínicas, salões de beleza, corredores de hospitais, provocando as pessoas a se envolverem, por entretenimento ou por outro motivo, com conteúdos diferenciados, atendendo a demandas de distintas naturezas;

- a cadeia produtiva do livro passa a ser valorizada como um negócio rentável, inclusive fazendo parte de estudos acadêmicos, como monografias, dissertações, teses, artigos, apresentados em eventos científicos ou publicados em revistas de variada natureza, onde se visualiza um novo olhar sobre esse segmento;

- instalação no Brasil e em diferentes países latino-americanos de grandes grupos editoriais;

- diminuição de compromissos tributários sobre os materiais de leitura no segmento editorial;

- a leitura passou a ser tratada pelo governo federal entre os Ministérios da Educação e da Cultura na perspectiva de assunto prioritário, configurando-se como um grande avanço no processo de formação de leitores;

- direcionamento de materiais de leitura e de equipamentos para as populações mais carentes;

- apoio de organismos internacionais como OEI, UNESCO, CERLALC às ações dos ministérios referidos.

Segundo Marques Neto (2010, p. 250), o PNLL apresentou até novembro de 2010 os seguintes resultados por eixo de atuação: 
Políticas públicas e ações de incentivo à leitura promovidas por organizações empresariais sob a ótica da responsabilidade social

Tabela 2 - Resultados do PNLL de 2006 a 2010

\begin{tabular}{|l|c|}
\hline Eixos de atuação & Quantidade de ações \\
\hline Democratização do acesso & 264 ações \\
\hline Fomento à leitura e à formação & 218 ações \\
\hline Valorização da leitura e da comunicação & 57 ações \\
\hline Apoio à economia do livro & 49 ações \\
\hline Calendário de Eventos & 244 ações \\
\hline Total de Ações & 832 ações \\
\hline
\end{tabular}

Fonte: Marques Neto (2010, p. 250)

Segundo Guaraldo (2015, p. 24), a partir de 2012, o PNLL se concentrou em ações mais descentralizadas com a realização de reuniões, seminários e encontros em todas as regiões do país.

No site do Sistema Nacional de Bibliotecas Públicas (SNBP) constam os Editais que selecionam projetos e iniciativas culturais no âmbito do livro, leitura, literatura e biblioteca e que receberão apoio no âmbito do próprio SNBP, Ministério da Cultura, entre outros.Em 2015, foram publicados os seguintes editais:

Tabela 3 - Editais de fomento ao livro, leitura, literatura e biblioteca em 2015

\begin{tabular}{|l|c|}
\hline Editais & Órgão responsável \\
\hline Prêmio Todos Por Um Brasil de Leitores (2015) & $\begin{array}{c}\text { SNBP e Ministério da } \\
\text { Cultura (MINC) }\end{array}$ \\
\hline $\begin{array}{l}\text { Edital de Fortalecimento do Sistema Nacional de Cultura } \\
\text { e do Sistema Nacional de Bibliotecas Públicas (2015) }\end{array}$ & SNBP \\
\hline $\begin{array}{l}\text { Prêmio às Boas Práticas e Inovação em Bibliotecas } \\
\text { Públicas (2014) }\end{array}$ & MINC \\
\hline $\begin{array}{l}\text { Apoio ao Circuito Nacional de Feiras de Livros e Eventos } \\
\text { Literários 2015 }\end{array}$ & IBERBIBLIOTECAS \\
\hline Programa IBERBIBLIOTECAS & \multicolumn{2}{|l}{} \\
\hline
\end{tabular}

Fonte: Sistema Nacional de Bibliotecas Públicas (2015)

Apesar dos esforços públicos para melhoria dos índices de leitura no Brasil, a última pesquisa Retratos da Leitura no Brasil (2011) evidenciou um piora na quantidade de livros lidos nos últimos três meses anteriores ao período da pesquisa, diminuindo de 3,7 em 2007 para 3,1 livros/ano em 2011.

Isso demonstra que além de políticas públicas, ações da iniciativa privada também são importantes para transformar o Brasil em um país de leitores.

Com relação as ações de incentivo à leitura nas organizações destacamos a Petrobras, empresa do setor de energia, que através da Seleção Pública Petrobras Cultural, oferece um programa de patrocínio a projetos culturais, contemplando iniciativas que vão desde a etapa de pré-produção até a do consumo final dos bens e serviços culturais e se fundamenta em três 
Adam Felipe Ferreira, Íris Marques Tavares Sardelari e Claudio Marcondes de Castro Filho

linhas de atuação: preservação e memória; produção e difusão; formação (PETROBRAS, 2015).

A Fundação Itaú Social, instituto do Itaú Unibanco, empresa do setor financeiro, mantém vários programas de incentivo à educação no país. Com o objetivo de colaborar para a melhoria do ensino e da escrita, o Programa Escrevendo o Futuro da Fundação desenvolveu, de 2002 a 2007, ações de formação aos professores da rede pública de $4^{\mathrm{a}}$ a $5^{\mathrm{a}}$ séries, a fim de orientar a produção de textos dos alunos e em parceira com o MEC, lançou a primeira edição da Olimpíada de Língua Portuguesa Escrevendo o Futuro (FUNDAÇÃO ITAÚ SOCIAL, 2012).

Além disso, o Itaú criou o projeto Itaú Criança. Nesse projeto, em 2015, a organização promoveu o slogan "Leia para uma criança: isso muda o mundo". Em 2015, no âmbito desse projeto, foram distribuídos mais de 4 milhões de livros infantis gratuitamente (ITAÚ, 2015).

O Banco do Brasil, empresa do setor financeiro, mantém a Biblioteca DIPES/Gepes, composta de uma rede de 9 bibliotecas setoriais e Biblioteca CCBB-RJ. Inaugurada em 1982, as bibliotecas oferecem serviços aos funcionários do Banco, por meio de empréstimos por malote. Seu objetivo é oferecer suporte ao ensino, à aprendizagem e às atividades da organização (BANCO DO BRASIL, 2015a,b).

Além das bibliotecas, o BB, no âmbito da Fundação Banco do Brasil, criou o Projeto Memória, que se configura como uma tecnologia social de educação que pretende difundir a obra de personalidades que contribuíram significativamente para a transformação social, a formação da identidade cultural brasileira e o desenvolvimento do país. São desenvolvidos produtos educativos, como a exposição itinerante que circula por centenas municípios brasileiros, o vídeo-documentário e o livro foto-biográfico que são dirigidos para bibliotecas públicas do País, além de um kit pedagógico, contendo almanaque histórico e guia do professor, destinado a 18 mil escolas públicas (FUNDAÇÃO BANCO DO BRASIL, 2011).

O Bradesco, banco privado, criou em 1956 a Fundação Bradesco, com o objetivo de promover a inclusão e o desenvolvimento social por meio da educação, priorizando o ensino de qualidade.

Em 2014, foram beneficiados nas escolas da rede 105.177 alunos. Essas escolas dispõem de Bibliotecas, que além de espaços de apoio, se constituem em ambientes de interação, nos quais o acesso a multimídias está a serviço do conhecimento (BRADESCO, 2015). 
Políticas públicas e ações de incentivo à leitura promovidas por organizações empresariais sob a ótica da responsabilidade social

A JBS, uma das grandes empresas de frigorífico do país, possui várias ações no âmbito da responsabilidade social e o exercício das práticas de sustentabilidade. De acordo com a pesquisa realizada no site em que divulga o relatório anual das atividades desenvolvidas pela Companhia, foi identificada uma ação relacionada com a educação no nível fundamental II e médio por meio do Instituto Germinare. No ano de 2014, a JBS repassou ao Instituto 7,9 milhões de reais para serem aplicados na educação, incluindo manutenção da biblioteca do Instituto. (JBS, 2014).

A Vale, empresa do setor de energia/minério, estimula diretamente atividades relacionadas ao desenvolvimento da educação e ao incentivo da leitura em nível local, promovendo o projeto social denominado "Trem da Vale", que se constitui em um programa de educação patrimonial que acontece nas estações de trem da cidade de Ouro Preto localizada no estado de Minas Gerais. Seu objetivo é valorizar a cultura oferecendo oficinas de leitura, sessões de contos de histórias (VALE 2015).

A companhia de multinegócios e de energia Ultrapar, por meio da empresa Ipiranga, mantém o programa "Semeando Cidadania", realizado em parceria com a Fundação D'Paschoal, que, desde o ano de 2004, já viabilizaram a distribuição de 1,3 milhão de livros sobre respeito, ética, cooperação e diversidade, beneficiando mais de 900 mil alunos de escolas públicas e instituições, em nível nacional abrangendo um total de 21 estados (ULTRAPAR, 2011). 


\section{Considerações finais}

As ações de incentivo à leitura da iniciativa privada juntamente com as políticas públicas desenvolvidas e implementadas no Brasil acontecem de forma muito tímida comparadas com a realidade desta sociedade, que possui em sua grande maioria indivíduos com dificuldades e limitações para a escrita, leitura e reflexão, conforme evidenciado no Indicador de Alfabetismo Funcional e na pesquisa Retratos da Leitura no Brasil apresentados neste artigo.

Essas questões precisam ser levadas em consideração de forma mais contundente, uma vez que as políticas públicas devem ser pensadas como um conjunto de ações que modifiquem de fato a realidade social, transformando as pessoas em agentes sociais, pois o pensar coletivo pautado na ética e na legalidade é elementar para o mundo contemporâneo.

É necessário trabalhar o conhecimento em sua totalidade, pois isso reflete diretamente na vida das pessoas, modificando e alterando padrões, exigindo uma nova maneira de pensar e agir perante o mundo.

A Competência em Informação transforma os indivíduos em seres sociais, detentores do próprio saber, transformando-os em agentes ativos e autônomos no que tange à informação, produção e disseminação do conhecimento em sua potencialidade.

A Era digital é incontestável nos dias de hoje, mas será que vivemos em um país globalizado? Ou vivemos em uma sociedade parcialmente evoluída no que se refere à ciência e à tecnologia? Será que a globalização vivida na sociedade brasileira é meramente parcial e acaba se transformando em um fator de exclusão e não de inclusão?

O governo em todos os seus níveis de atuação (municipal, estadual e federal) tem o dever de promover ações e políticas para o desenvolvimento da leitura e do aprendizado, nesse sentido, ressalta-se a importância do papel das organizações empresariais, pois para haver progresso e crescimento é necessário convergência entre metas econômicas e sociais.

Diante disso, concluímos que, para a promoção da leitura em nosso país, é imprescindível o pensar sustentável, o exercício da cidadania e a busca pelo aprendizado ao longo da vida, pois o ambiente atual anseia por ações de extensão mais ativas com base em uma visão integralizadora sob a ótica da responsabilidade social. 
Políticas públicas e ações de incentivo à leitura promovidas por organizações empresariais sob a ótica da responsabilidade social

\section{Referências}

ANDRADE, M. M. Introdução à metodologia do trabalho científico. São Paulo: Atlas, 2009.

ASHLEY, P. A. Ética e responsabilidade social nos negócios. São Paulo: Saraiva, 2002.

BANCO DO BRASIL. A biblioteca. 2015a. Disponível em: $<$ http://www.bb.com.br/portalbb/page3,139,9189,23,0,1,8.bb?codigoNoticia=27157\&codi goMenu=5990> . Acesso em: 20 nov. 2015a.

Conheça a biblioteca. 2015b. Disponível em:

$\langle$ https://www.unibb.com.br/Customizacao/IntroducaoAlexandria.aspx $>$. Acesso em: 20 nov. 2015 b.

BELLUZZO, R.C.B. Relatório final apresentado ao Programa de Pós-Doutorado em Gestão Escolar. Araraquara: Faculdade de Filosofia, Ciências e Letras de, 2005.

O conhecimento, as redes e a competência em informação (CoInfo) na sociedade contemporânea: uma proposta de articulação conceitual. Perspectivas em Gestão \& Conhecimento, João Pessoa, v. 4, Número Especial, p. 48-63, out. 2014.

BRADESCO. Fundação Bradesco. 2015. Disponível em: 〈http://www.fb.org.br/〉. Acesso em: 20 nov. 2015.

CASTELLS, M. A sociedade em rede. São Paulo: Paz e Terra, 1999.

CASTRO FILHO, C. M. Os caminhos da biblioteca escolar. In: ROMÃO, L. M. S. Sentidos da biblioteca escolar. São Carlos: Alphabeto, 2008.

.; ROMÃO, L. M. S. Livros-ninhos e leituras-passarinhos: outros sentidos do documento. In: CRIPPA, G.; MOSTAFA, S. P. Ciência da informação e documentação. Campinas: Alínea, 2011. p. 131-141.

COUTINHO, C.; LISBÔA, E. Sociedade da informação, do conhecimento e da aprendizagem: desafios para educação no século XXI. Revista de Educação, v. 28, n. 1, p. 522, 2011. Disponível em:

<http://repositorium.sdum.uminho.pt/bitstream/1822/14854/1/Revista_Educa\%C3\%A7\%C3 \%A3o,VolXVIII,n\%C2\%BA1_5-22.pdf>.Acesso em: 20 nov. 2015.

INSTITUTO ETHOS - Instituto de Empresas e Responsabilidade Social. Indicadores Ethos para negócios sustentáveis e responsáveis. São Paulo: Instituto Ethos, 2016. Disponível em: 〈http://www3.ethos.org.br/wp-content/uploads/2014/10/Indicadores-EthosNSR_-2015.pdf>. Acesso em: 25mai. 2016.

FUNDAÇÃO BANCO DO BRASIL. Projeto memória. 10 jun. 2011.Disponível em: <http://www.fbb.org.br/acoes-programas/educacao/projeto-memoria>. Acesso em: 20 nov. 2015. 
Adam Felipe Ferreira, Íris Marques Tavares Sardelari e Claudio Marcondes de Castro Filho

FUNDAÇÃO ITAÚ SOCIAL. Olimpíada de língua portuguesa escrevendo o futuro: textos finalistas: edição 2012. 2012.Disponível em: <http://fundacao-itau-socialproducao.s3.amazonaws.com/files/s3fspublic/biblioteca/documentos/2012_livro.pdf?CyVBJfNmBBhD6uzJE2ve44fH6saLQQAw>. Acesso em: 20 nov. 2015.

Campanha receite um livro é lançada em congresso de pediatria. 2015.

Disponível em: <http://www.fundacaoitausocial.org.br/pt-br/acontece/noticias/campanhareceite-um-livro-e-lancada-em-congresso-de-pediatria>.Acessoem: 20 nov. 2015.

GUARALDO, T. S. B. Práctica de lectura en Brasil: un análisis del PNLL desde la comunicación. La Trama de la Comunicación, v. 19, enero a diciembre de 2015, p. 15-27.

HOLANDA, A. B.; OLIVEIRA, M. C. G.; OLIVEIRA, S. R. Incentivo à cultura:experiências brasileiras de políticas públicas: interesses da Ciência da Informação. TransInformação, Campinas, v. 25, n. 1, p. 47-53, jan./abr., 2013.

INAF. INAF Brasil 2011: principais resultados. São Paulo, 2012.

INSTITUTO PRÓ-LIVRO. Retratos da leitura no Brasil: 2011. 3. ed. São Paulo: IPL, 2012.

ITAÚ. Itaú criança. 2015. Disponível em: 〈https://www.itau.com.br/crianca〉. Acesso em: 20 nov. 2015.

JBS. Relatório anual e de sustentabilidade. 2014. Disponível em:

<http://relatorioanual.jbs.com.br/comunidade/>. Acesso em 25 mai. 2016.

MANGUEL, A. Uma história da leitura. São Paulo: Companhia das Letras, 1997.

MARQUES NETO, J. C. Realizações. In: MARQUES NETO, J. C. PNLL: textos e histórias. São Paulo: Cultura Acadêmica, 2010, p. 245-251.

MELO NETO, F. P.; FROES, C. Gestão da responsabilidade social corporativa: o caso brasileiro. Rio de janeiro: Qualitymark, 2001.

OLIVEIRA, A. D.; PRADOS, R. M. N. Políticas públicas para o livro, leitura, literatura e biblioteca no Brasil. Información, cultura y sociedad, Instituto de Investigaciones Bibliotecológicas, ed. 32, p. 99-112, junio 2015.

PETROBRÁS. Programa Petrobrás cultural. 2015. Disponível em:

<http://ppc.petrobras.com.br/>. Acesso em: 20 nov. 2015.

PNLL. Caderno do PNLL. Ed. rev. atual. Brasília: MinC, 2014.

RIBEIRO, A. E. Ler na tela: o que é, hoje, um livro? In: MARTINS, A. A. et. al. Livros \&telas. Belo Horizonte: UFMG, 2011. p. 93-106.

RÖSING, T. M. K. PNLL: conquistas e desdobramentos. In: MARQUES NETO, J. C.

PNLL: textos e histórias. São Paulo: Cultura Acadêmica, 2010, p.235-240. 
Políticas públicas e ações de incentivo à leitura promovidas por organizações empresariais sob a ótica da responsabilidade social

SALOMÃO, K. As 7 empresas brasileiras entre as maiores do mundo em 2015. Exame.com: revista Exame, 22 jul. 2015. Disponível em: <http://exame.abril.com.br/negocios/noticias/asmaiores-empresas-brasileiras-em-2015-segundo-a-fortune\#7>. Acesso em: 20 nov. 2015.

SARAVIA, E. O conceito de política pública. In: SARAVIA, E.; FERRAREZI, E. (Org.). Políticas públicas: coletânea. Brasília: ENAP, 2006.v. 1.

SECCHI, L. Políticas públicas: conceitos, esquemas de análise, casos práticos. São Paulo: Cengage Learning, 2014.

SISTEMA NACIONAL DE BIBLIOTECAS PÚBLICAS. Editais. 2015. Disponível em: $<$ http://snbp.culturadigital.br/editais $>$. Acesso em 20 nov. 2015.

ULTRAPAR. Relatório de responsabilidade social. 2011. Disponível em:

<http://www.ultra.com.br/Ultra/relatorio/2011/br/base.asp?Capitulo=desempenho $>$. Acesso em 26 nov. 2015.

VALE. Trem da Vale. 2014. Disponível em:

http://www.vale.com/brasil/pt/aboutvale/patrocinios/projetospatrocinados/paginas/default.asp x. Acesso em 26 nov. 2015.

WETHEIN, J. Leitura e cidadania. In: AMORIN, G. Retratos da leitura do Brasil. São Paulo: Imprensa Oficial, 2008. 